\title{
Health Seeking Processes of Leprosy Patients in a Hill District of Nepal
}

\section{Dr.Ulla-Britt Engelbrektsson ${ }^{*} \&$ Prof. Madhusudan Subedi ${ }^{\dagger}$}

\begin{abstract}
To shorten delays in leprosy diagnosis, health-seeking processes have to be understood and documented. In 2015, the International Nepal Fellowship launched a three-year research project on the subject. One part of the project was a community study in which recent health-seeking efforts were to be studied in the light of earlier ones. The focus of this article is upon insights gained in field research in a village and its immediate surroundings in the district of Jajarkot, western Nepal. The result is a longitudinal, patient-focused study that covers the period from just before the start ofleprosy services until late 2018. The research methods include participant observations, narratives, in depth interviews, and documentary and statistical enquiries. The research shows that the introduction of the Multi Drug Therapy (MDT) in the early 1980s has drastically changed the local leprosy diagnosing. The number of new cases has declined, there are far less impairments and disabilities, and those recognized as affected are no longer excommunicated. However, the delays before diagnosis tend to be long. A lack of leprosy being present diagnosing skills within the health services sector is one reason. The residents not recognizing early signs and symptoms is another. An expectation of leprosy being endemic in certain kinship groups, and not in others, is yet another.

* Ulla-Britt Engelbrektsson (PhD in Social Anthropology, 1979). Associate Professor since 1998 at the University of Gothenburg, Sweden. After retirement in 2009, she is an independent researcher. Currently, she is associated with the Shining Hospital INF Surkhet, Nepal.

Email: ulla-britt.engelbrektsson@inf.org

$\dagger$ Mr. Madhusudan Subedi is Professor and Chairperson of the Department of Community Health Sciences and Coordinator of the School of Public Health, Patan Academy of Health Sciences. He is also associated with the Central Department of Sociology, Tribhuvan University, Nepal.

Email: madhusudansubedi@gmail.com
\end{abstract}


And, for some, so is the fear of social stigma. Moreover, there is the delaying factor of more than one set of beliefs and practices in relation to leprosy: a traditional mainly magic-religious outlook co-existing with allopathic (biomedical) views and methods.

Keywords: leprosy health-seeking, leprosy related beliefs, delays in leprosy diagnosis, social stigma, Nepal

\section{Introduction}

This section highlights the background of the study, the research project and earlier research in the area.

At the start of the National Leprosy Programme in Nepal (1974), the Government asked the International Nepal Fellowship (INF) to assist in the western half of the country. INF's work in the district of Jajarkot started five years later with various surveys. A year later, as one of the outcomes of the surveys, the district leprosy prevalence was estimated to be 157 cases per 10,000 population (International Nepal Fellowship, 1981). Shortly after, INF allocated a leprosy supervisor to work alongside government staff. The arrangement continued over the next 25 years.

In 2009, shortly before the official proclamation of 'leprosy elimination at a national level' (less than one person on leprosy treatment per 10,000 population at a specific date), the recorded point prevalence ratio for Jajarkot was 2.04 per 10,000 population (Leprosy Control Division, 2010). Seven years later, in 2016/17, with a total of 46 patients on leprosy treatment throughout the year, according to official statistics, the leprosy point prevalence for Jajarkot was 1.28 per 10,000 population (Leprosy Control Division, 2017). Parts of the recorded declines reflect the ending of a huge backlog and changes in definitions and in lengths of treatments (early treatments longer than later ones). Even so, Nepal has come a long way in combatting the disease. However, there is still some way to go.

\section{The research project}

To assist in the battle against leprosy, in early 2015, INF launched a research project in the western part of the country entitled "Delays in Diagnosis and Treatment, Leprosy in Nepal" ('the Delay project') (Subedi 2018; Engelbrektsson et al. 2019). Included in the project was a community study in which current health-seeking efforts were to be researched in the light of those of an earlier date. The community chosen was the rural community of Dhobata in the hill district of Jajarkot. Previous studies of leprosy health- 
seeking in Nepal were few, and rarely not from the western part.

In Jajarkot, as in the rest of the country, most leprosy patients present voluntarily. Long delays aggregate negative consequences for individual and families and, in cases of infectious leprosy, increase the risk of the spread of the disease.

\section{Earlier research in the area}

The choice of community was steered by the existence of earlier leprosy-related studies in the area. INF's 1979/80 surveys in Jajarkot included active case finding surveys which, in some places, were combined with health education and a preand post-health education survey, the Leprosy Knowledge and Attitude Survey. One of the ten randomly selected sites for the latter was a ward within the Dhobata Village Panchyat. At each site, a pre-decided number of residents were interviewed face-to-face with the help of a mainly multiple choice questionnaire on the cause of leprosy, attitudes concerning leprosy, and expected behavior towards those affected. There was no final report on the outcome but in 1996 (see below), the reply data from six of the ten sites were recovered and analyzed. Shortly after the surveys, in Dhobata and its neighboring villages, Dr Robert Cardinalli, a social anthropologist, and his team, using both in-depth anthropological methods and quantitative survey techniques, time-allocation mapping in particular, researched the economic roles and the social status of leprosy affected persons within their families and within the wider social group. The studies in the field stretched over a year. The findings are presented in a massive unpublished report from 1982 (Cardinalli, 1982). And, 15 years later, in 1996, the main author of this article, also a social anthropologist, studied the situations of leprosy affected persons and families in Dhobata and its neighboring villages. The area was re-visited in 2009 and in 2010 and subject-relevant information on what had taken place since the earlier studies was gathered and new patients were identified and interviewed. In addition, in 2010, INF's earlier Leprosy Knowledge and Attitude survey was repeated in the previously surveyed Dhobata ward. The main findings from 1996 and the 2009 and 2010 follow-ups are reported on in a chapter of its own in a monograph by the first author of this article, published in 2012 (Engelbrektsson, 2012). Thus, there were leprosy-related ethnographic data to build upon and established networks to draw upon for the envisioned community study.

\section{The study site}

The village of Dhobata is situated north-east of the district headquarters, the Jajarkot Khalanga, at an altitude of $3,500 \mathrm{~m}$. There are two other villages and one sizeable off-shoot hamlet within one hour's walking distance. The four settlements are ordinary Hindu Parbatiya (hill people) communities. The 
settlement patterns are dense. The primary means of livelihood was and is high altitude farming supplemented by animal husbandry. Land holdings are small. To make ends meet, dispensable men go south, mainly to India, for seasonal work and of late even further abroad and for longer periods of time. In each village, the high castes form a majority and have the economic, social, and political power. Families from the same lineage tend to live close to each other with frequent interaction. At the same time, social visiting between non-related households is limited and non-existent across caste boundaries.

In 1996, Dhobata, the largest unit, contained 89 households. There was a village school and radios but no electricity. Seventy percent of the high caste households had someone literate in the house whereas the same was true for only $20 \%$ of the Dalit ('low caste') ones. A day of hard walking on a dirt track was needed to reach the district headquarters. In 2018, there were somewhat more than 100 households, a paved road with bus transport to the district headquarters, solar panel electricity, and mobile phones. Alongside a higher level government school, there was also a private alternative and, most likely, at least one literate person per household.

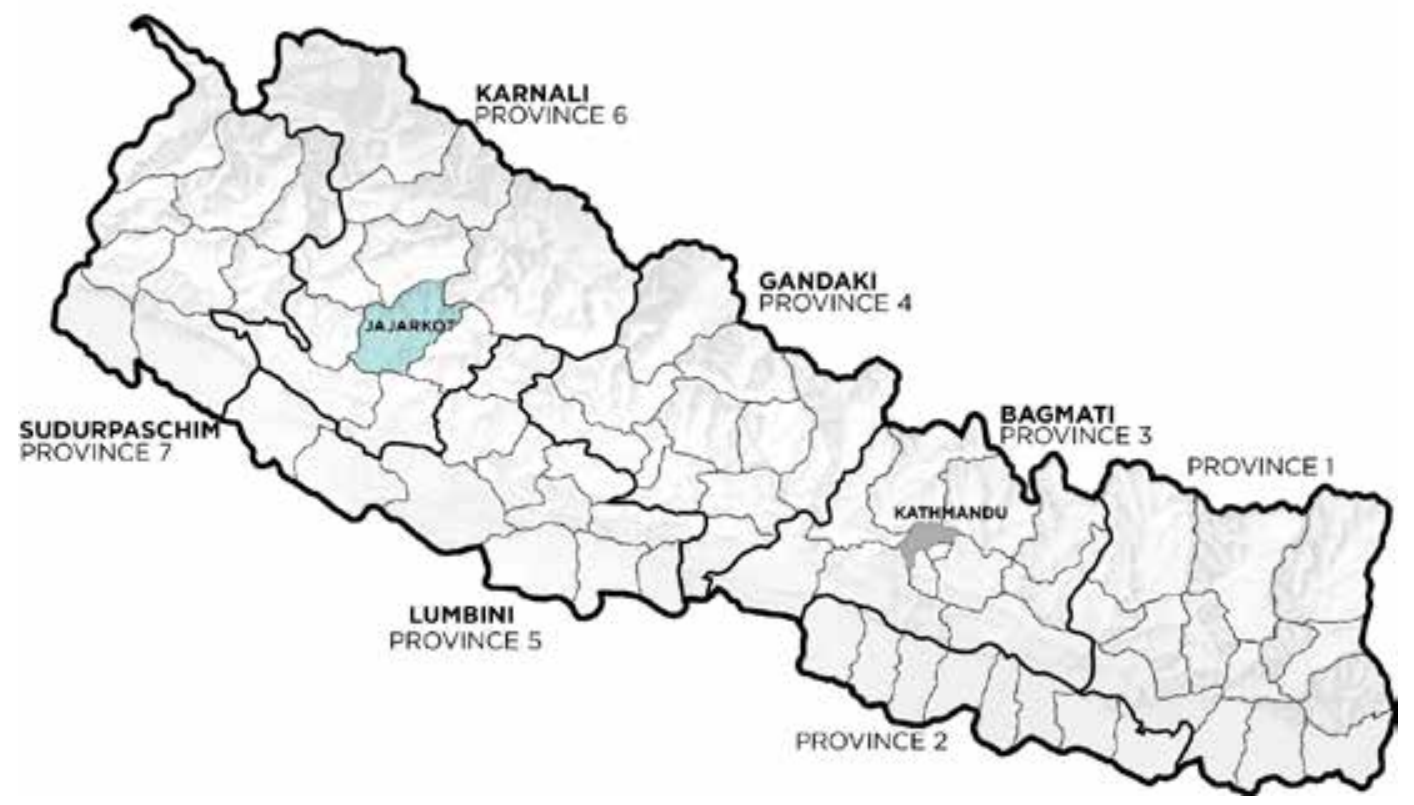

The Map 


\section{Material and methods}

Diverse material from the 1979/80 INF surveys found in one of the INF offices in Pokhara in early 1996, together with consultations with the supervisor of the Jajarkot Leprosy Knowledge and Attitude Survey and information found in the unpublished report by Dr Cardinalli, provided background information to the 1996 one-month field research with week-long follow-ups in 2009 and 2010. Histories of older and recent leprosy cases were gathered and when possible reviewed with those most directly involved: the person affected and family members. Medical records were scrutinized and discussed with local health workers. In addition, data located from INF's 1979/80 Knowledge and Attitude survey was statistically analyzed and examined.

Health-seeking processes were not a key topic in the material at hand, yet it contained subject-relevant information. In the 2016 field study and its follow-ups, some of the earlier interviewed patients were re-interviewed, now with a focus on health-seeking processes, and later patients were approached and interviewed about their health-seeking efforts, all in order to identify and document major factors of influence for leprosy delays over time within a local context, in this case the Dhobata area in the Hill district of Jajarkot.

In the later study, in 2016, and in the 2018 follow-ups, local health workers were contacted and various registers and patient files were examined. Homes were visited and key informants were questioned. Kinship charts were drawn and patients were interviewed face-to-face with the help of a pre-tested interview guide at a time and place convenient for them. Those approached were informed about the purpose of the study, that participation was voluntary, that interview information was confidential, and that there would be no reimbursement. Most respondents were met with more than once.

The historical period covered by the various research undertakings stretches from just before the start of local leprosy services until late 2018. Insights gained are presented as a longitudinal study in the form of a time-sequenced narrative, mainly organized around the 1996 study and its follow-ups and the 2016 study and its follow-ups. Both studies were headed by the first author of the present article, assisted by senior INF leprosy staff. The account is patient-focused. Being a mainly qualitative narrative, selected illustrations are used to exemplify general insights and conclusions (see Ogden and Porter, 1999; Subedi 2018; Engelbrektsson et al. 2019). To protect the anonymity of persons, the names of places have been altered. 
The ethnographic focus of the study is on leprosy-related ideas, experiences, and practices of one local area in one of Nepal's remote districts -this limits the extent to which the findings can be generalized. However, the insights gained are expected to be valid for similar socio-cultural contexts of Nepal, in particular the Hindu Parbatiya (hill people) communities.

\section{Major findings}

Being a longitudinal study, the findings are presented in a time sequence.

\section{Prior to the arrival of local treatment}

Before the opening of the national borders of the Hindu kingdom of Nepal in 1951, health services for most residents, those in Jajarkot included, were primarily dispensed by shamans, priests, and herbalists. The first effective anti-leprosy drug, dapsone (DDS), reached Jajarkot in the late 1970s.

Pipalbot, one of the villages next to Dhobata, was particularly hard hit by leprosy. In the mid-1970s, a group of nine leprosy patients from Pipalbot together with two from another village led by a hired man from Dhobata (not leprosy affected), set out for Nepal's capital in search of treatment. Twenty years later, the man from Dhobata recounted:

"We walked slowly as some had troubles with their feet and others had bad eyesight. Some had deformities and some had ulcers, and people along the route were alarmed and told us not to get close. The youngest was twelve, the oldest nearly sixty. We brought provisions but had to buy some food and that was not easy as people did not want to sell to us. It took us 15 days to reach Raxaul (just inside India). From there we tried to get a bus to Kathmandu but the drivers didn't want us. Finally, I pushed them all into one bus. The bus owner was very angry and hit me with a shoe but we stayed put. We paid double fees and were taken along. We were in the back of the bus. It was dark when we arrived in Kathmandu. We started walking early the next morning and 24 hours later we arrived at the Anandaban hospital (the Leprosy Mission) where we were nicely received. Some were admitted, whereas others stayed just outside the hospital. A few weeks later, we started the return journey, some with medicines for one year, others with medicines for two years."

Most of those affected at the time, however, did not have the means to seek help outside the district and gradually their physical condition would deteriorate and because of it so would their social situation. In 1996, the next-door neighbor of our Dhobata host reported that some forty years 
earlier, first his mother and then his maternal uncle were forced out of the village because of leprosy and some years later, so was his sister who had married into the off-shoot hamlet of Dhobata. "We cried and we feared the disease would come to us also. No one came near our house." His sister was twenty years of age when there were signs of leprosy. One shaman after another was consulted. Finally, one said, "I am the god who gave this disease to your daughter. If you give me another daughter (for the shaman's son to marry) I will take this disease away!" Their father (high caste) gave the youngest daughter to the shaman's son (not high caste). She died in fever within a year. Shortly after, the leprosy affected daughter was excommunicated. She was 25 years of age when found dead in her shelter in the forest.

In his report (1982), Dr Cardinalli notes that leprosy treatment had been available from the Jajarkot district hospital for some years. Supplies of drugs, however, were very irregular, and the hospital was usually not manned by doctors or technicians who were trained in the diagnosis and treatment of leprosy ( $p$ 94). Locally, he writes, leprosy was generally believed to be a punishment for sins and misdeeds committed in one's past life or lives ( $p$ 321). And, for those recognized as affected, there was a heavy loss of status both within and outside the household. He concludes: " ... the disease of leprosy is as much a social, cultural and psychological problem as it is a medical one" (p 313).

Dr Cardinalli reports that the traditional community response to leprosy was avoidance and separation. Meanwhile, those affected were shy to display themselves in public. At the same time, the dominant patriarchal social structure gave male patients a better chance to withstand social pressure than females. However, because of the caste hierarchy, some males were socially more vulnerable than others. Thus, Dr Cardinalli says that those forced to live outside the village because of leprosy were mainly women and low caste men, and primarily those whose physical conditions were such that they were no longer able to contribute to the household economy ( $p 136)$.

In 1996, the before mentioned neighbor of our Dhobata host and others besides him reckoned that during his 60-year lifetime there had been 25 leprosy affected persons in Dhobata and its off-shoot hamlet. Only four were women. Except the six still present in the village, all had been put out or had left the area. Some had taken their own lives. "The big change," he said, "came with the team from Kathmandu and with the medicines."

The 1979/80 INF health-education survey supervisor, Mr Mukhti Sharma, met with and interviewed in 1996, told that the surveying had been far from 
easy as the people in Jajarkot were afraid of outsiders, there was a scarcity of food, and the terrain was extremely challenging. Notwithstanding, with six months in between, the pre- and the post-surveys (same questions), were carried out in ten wards, in each with a minimum of 40 respondents (half males, half under the age of 30). The idea of half having formal or informal education equal to an $8^{\text {th }}$ class level was abandoned as there were too few around to meet the criteria. The one-hour health education programme was carried out not only in the survey-sample wards but in all the wards within their administrative units, i.e. also in Dhobata proper.

In 1996, as mentioned, the completed reply sheets from six of the ten wards were rediscovered and the data scrutinized and statistically analyzed on a ward basis as well as a whole. There were some variances, but the most striking feature was the uniformity in replies. The reply sheets from the ward within the Dhobata administrative unit were not found. However, Mr Sharma, testified to the replies from this ward not having differed from those of the other wards.

The main purpose of the Leprosy Knowledge and Attitude survey was to evaluate the impact of the health education efforts. When interviewed in 1996, Mr Sharma expressed a deep disappointment with the outcome. "Knowledge was changed but not attitudes!" he said, a statement to which he provided numerous examples. The same conclusion he expressed at the time in a dispatch to the main organizers. In regard to those excommunicated, he wrote, "It is said that if cured from deformities they can stay in society but otherwise not!" And, about those not yet excommunicated, "...even when they know that a patient is on treatment, they will not touch him or her!" To us he concluded, "Only head-knowledge was changed - not attitudes and behavior!"

The pre-education survey results revealed that leprosy, believed to be contagious; inherited; a curse by the gods; fate; and due to attacks by ghosts/spirits, was by far the most feared condition ( $>$ than $90 \%$ ) in the district. The post-education survey results showed that the health education message about 'germs' (kitaunu minute animals) had landed but only as one possible cause among others.

\section{The early days of local treatment}

MrSharma reported that at the time of the surveys, early signs and symptoms of the disease were not recognized as leprosy. "To them," he said, "a person affected by leprosy was a person 'like a $\log ^{\prime}$ - a person without hands and feet." However, if there was known leprosy in a family, even those in an earlier 
stage of the disease could be ousted. "Our key message", he said, "was that leprosy was curable and when on medicines no need to put anyone out."

The nearest public health facility, the Gukulpur Health Post, served four administrative units, Dhobata with its neighboring villages being one of them. Before the arrival of the INF teams its leprosy register contained four patients registered for treatment. A year later the number was 80 .

The treatment (dapsone, DDS) was free of charge. Even so, not everyone affected wanted to be enrolled. A case in point was a well-known shaman and his daughter in one of the villages next to Dhobata. The shaman never showed up for an examination. The husband of his daughter, however, had his family examined. Three out of seven family members were found to be leprosy affected and were registered for treatment. The husband, a renowned shaman himself, and the son got started. The wife, however, refused to do so. She even had her examination card removed from the Health Post. She, like her father, claimed that her condition was not leprosy but 'a leprosy-like condition' imposed by the gods and therefore spiritual rituals (pooja) not medicines were called for.

In spite of the survey supervisor's disappointment, their messages of leprosy being curable and non-infectious after start of treatment had an impact, at least in Dhobata. Thus, shortly after the INF teams had left, the men of the village met and discussed what they had seen and heard. The decision made was to wait and observe what happened to those who were started on medicines. About 18 months later, the decision was that from then on 'the community' would not excommunicate anyone on leprosy medicines. Not everyone was happy with the decision, but it was taken. On our arrival fifteen years later, within the Dhobata administrative unit, only one person, a Dalit ('a low caste') woman, lived outside the community because of leprosy.

\section{In 1996}

The terrain was as challenging as earlier, the previous fear of outsiders, however, was no longer prominent. A letter of introduction from the district leader of the Red Cross, and certificates from Tribhuvan University and from the Regional health authorities resulted in the official Dhobata village leader welcoming us and our research, even to the degree that he made arrangements for us to live in one of his houses. He and his relatives even paved the way for multiple contacts within and outside the village. To government health service staff 'INF' was a known entity, the INF hospitals, in particular and our linkage to these, ensured good co-operation. 
Ill-health flourished in Dhobata and adjacent villages. Shamans (dhami/jhankri) counteracted malevolent spiritual forces, herbalists/bonesetters treated men and animals, pandits (Hindu priests) recited scripture portions and provided protective charms, and a few low-grade government health workers dispensed medicines to those who made their way to the Health Post. The Dhobata pandit suggested that according to ancient Hindu scriptures there were several types of leprosy. And he himself, he said, had cured some of the lesser ones.

In 1996, there were altogether 128 names in Gukulpur Health Post's leprosy register. The names suggested that three-quarters were of a high caste background, one quarter Dalits, and two of an ethnic group background. This was in line with the general caste distribution of the area but the male/female ratio was clearly unbalanced with three males to every female.

The registered addresses indicated that 28 were from the Dhobata administrative unit. Of those, one person was probably from somewhere else. Four had left the area. Five had died. Eighteen were still around. We met and interviewed 15 of them and two who had registered and had their treatment elsewhere, and one who had had treatment without registration:18 persons in total with three being women. During the follow-ups in 2009 and 2010, the situations of most of those previously interviewed were followed up and four new patients were included in the cohort, one of them a woman.

A surprising discovery in the Health Post's records was that almost 70\% of those registered (63 M, 22 F) were classified as 'Out of Control' (OC). Some had died before having finished the treatment and others had moved away. Even so, obviously a large proportion of those who had started treatment did not complete it, at least not then and there.

In Dhobata, the suggested main reason for the high rate of defaulting was that several of those registered were persons with deformities and when they realized that the medicines would not 'cure' their deformities, they defaulted. In addition, the Health Post was not easy to reach, the staff were not friendly (they did not touch the leprosy patients and kept them waiting), and rumors suggested that the medicines were out of date.

The village decision had been that, after the start of treatment, no one would be expelled as long as his/ her condition did not deteriorate. However, a new ulcer and the like were understood as the disease not having been properly 'killed' and thus a need for more medicines. And, over the years, many of those originally written off as 'OC' were restarted on leprosy medicines, 
some more than once. Meanwhile, the more effective Multi Drug Therapy (MDT) with shorter treatment periods had arrived.

One outcome of the INF case detection survey was the start of a monthly leprosy clinic at Gukulpur Health Post. It continued for more than twenty years. However, by the time of our stay it had come to an end and suspect cases were referred to the District hospital for diagnosing.

In Dhobata, 'leprosy' (kor/kushta rog/maha rog), like all major negative drawbacks in life, was perceived as an earned condition for misdeeds in this or in an earlier life (the law of Karma). To be affected by leprosy was to be in an inauspicious state and in a ritually polluted condition. Thus, there should be avoidance, and 'no touch'. However, with excommunication no longer an alternative, leprosy and its carriers had to be lived with.

In a general sense, all leprosy was perceived as a curse by the gods according to the law of Karma. However, at the same time, there was the notion of some leprosy possibly or likely being directly imposed by lesser gods (from the outside), the 'deity-caused' (deotalagyo/dokh) type, in contrast to a more 'disease type' leprosy (from inside the body/rog). Whereas the latter type would benefit from 'Western medicines' the former would not. In fact, the causative deity might well resent a medical intervention.

In real life, it was not always easy to know which type was at hand. A case in point was a man (high caste) in Dhobata's off-shoot hamlet who claimed that his condition was 'deotalagyo', whereas many of his neighbors thought otherwise. They, however, did not dare to challenge him and that in spite of his mother previously having been forced out of the village because of leprosy. The man's face was red and swollen and there were ulcers. We were told that if the Ward Member would tell him to move out he would probably reply, "It is not your business, I am not living in your house!" Later, however, we learnt that unknown to the community and even to his mother and brother, alongside magic-religious consultations and sessions, he had leprosy medicines both from India and the District hospital.

In the village of the earlier mentioned leprosy affected powerful shaman who refused to be enrolled for allopathic treatment, there was a teacher who had assisted the INF teams in their work and in doing so he had acquired a good knowledge of leprosy. A few years before we met, he (high caste) had suspected leprosy in a Dalit fellow villager and had sent him to the Health Post for a diagnosis. In 1996, he wanted us to examine and advise a relative of his. The teacher was convinced that his relative had leprosy but 
being of a younger generation he could not advise this older relative to go to the District hospital. We obliged and clearly it was leprosy. A week later, the same teacher told us about 'a god' (deota) who had healed a severely deformed leprosy affected person. When in serious trouble, his family (the teacher's family) had for generations turned to a specific god in their village of origin. In their present village, his parents, he told, had had a neighbor severely affected by leprosy who had been to one shaman (dhami/jhankri) after another without the desired result. Finally, the teacher's grandfather had brought him to the god in their village of origin (to the shaman of that god). Animals were sacrificed and straight away the man started to get better. Thus, his collapsed nose became more normal and his clawed fingers began to straighten out, and over the next few months he was completely healed. The teacher, as far as we understood, believed it fully. We, however, had not expected such a story from such a person. He however, like many of the villagers, had an open mind to parallel explanations and suggestions.

In 1996, only four persons were on leprosy treatment from the Gukulpur Health Post, none of them from our primary study area. One person, however, was in the pipeline, a Kami (iron-smith). Our host, the village leader, had spotted his condition and had quietly advised him to go to the Health Post. What our host did not know was that he had already been there and had been told to go to the District hospital for a leprosy examination. This, however, he had not done. One finger was shortened but hidden underneath a bandage, there was a plantar ulcer, and there was jhum-jhum (tingling/thudding nerve pain). He had been to one shaman in particular and several goats had been sacrificed. Finally, the shaman had told him that his condition was because the god of one of his pieces of land (he only had a few) was against him and he should have nothing to do with that plot of land. He followed the advice.

At the same time, in Dhobata proper, there were six persons known to have been on leprosy medicines, some visibly marked by the disease and others not. They were not openly avoided but some villagers kept a distance. "Seventy-five percent," it was said, "were fairly convinced that because of the medicines they were no longer a danger to anyone but twenty-five percent were not." "Relatives," it was said and observed, "showed a smiling face but were not eager for them to visit." Meanwhile, those affected were careful not to challenge the good will of others and ardent in their efforts to come across as being in good health.

The official message was: "leprosy is curable" (kushtarog niko huncha)! To the medically minded or trained the expression meant the killing off of the 
leprosy bacteria, but to most locals the expression meant the disappearance of signs and symptoms, a result not always achieved. In many cases there were more questions than answers; a situation clearly demonstrated in the case of the woman who lived outside the community because of leprosy. She resembled the traditional stereotype of 'no hands and feet'. She said that this was the case already in 1980 when she was started on leprosy medicines (dapsone). She defaulted within a year. There were two restarts. And in connection with the last one, according to the register, she was 'released from treatment' (RFT = medically cured). "Do you still have leprosy?" we asked. "I think not but I am not sure," she said. The reason she thought that her leprosy might be gone was that previously blisters would not heal but now they did. The villagers, however, did not believe she was cured. "If cured she should have fingers," they said. She had a daughter in the village. The daughter knew that her mother had taken medicines for several years but did not know if they were sufficient or not. "I am afraid of the disease, but not of my mother," she said.

In 1996, when leaving Pipalbot (the main village of the group who twenty years earlier headed for Kathmandu in search of treatment), we were approached by some locals wanting to talk with us. They reckoned that presently there were five persons affected by leprosy in the village and they wanted to know if they were 'safe' or not? The five had been on medicines but even so they had noticed that sitting at the same distance from the fire, ' $X$ ' developed blisters whereas they did not. "We try to play it as safe as possible," they said, "but the village is small and sometimes we end up rubbing shoulders with those affected and involuntarily we touch things they have touched." "Will it come to us?" they wondered.

\section{In 2009 and 2010}

In the Civil War (1996-2006), the district of Jajarkot was a stronghold for Maoist rule and activities. In Dhobata, a local Dalit was installed as village leader. The Maoists propagated against the healing methods of shamans and pandits. Meanwhile, an allopathic Sub-Health Post was set up.

In spite of the presence of the Sub-Health Post and frequent health messages during the Maoist era, the understanding of the allopathic approach was extremely limited. Having learnt that we were medically trained, people kept asking us for medicine for this and that, seemingly completely unaware of the need for detailed information and/or an examination for the right treatment. To most, the working of Western drugs was obviously as mysterious and miraculous as any shamanistic intervention, perhaps even more so! 
Seemingly, the decision where to turn for help when ill or injured was mostly a matter of convenience. During clinic hours, many would turn to the Sub-Health Post. If not satisfied, the next step could be a consultation with a shaman and/or a trip to a newly opened medicine shop a few hours away.

Leprosy medicines, it was said, had a good effect on many but not necessarily on everyone. Moreover, the conditions of some who had improved with medicines had not remained stable. If 'cured' by medicines, how could that be? And, contrary to expectations there had been new cases, yet they had understood that after the start of medical treatment a person would not be infectious! The transmission of a disease from one person to another was a known phenomenon but prolonged incubation periods were not.

The Gukulpur Health Post was flooded in 2007 and its leprosy register was lost. In 2009, in the new register, there were only three entries for the Dhobata administrative unit: two 'released from treatment' (RFT) and one 'on treatment'.

The one 'on treatment' was a man in his early twenties who, in 2009, accompanied by his father, came to our house late one evening. He reported that quite suddenly there had been nodules on his face and shortly after he had been to a hospital in a neighboring district. To his surprise he was told that it was leprosy. "But, no leprosy in our kinship group," he said, "so how could it be leprosy?" Not believing the diagnosis he had turned to the Jajarkot District hospital. He arrived while a leprosy case validation team was at work. According to him, he was simply handed a letter for the Gukulpur Health Post, together with a prescription for medicines for a total cost of NRs 3,000 (a large sum for a Jajarkot villager). At the Health Post he was immediately started on leprosy treatment. Now he had come to us and asked, "If leprosy, why all these other medicines?" His family name suggested a possible patrilineal link to a leprosy affected person who earlier had lived and died outside their village. "Yes", the father said, "He was my father's brother's son." So why did they say that there had been no leprosy among their relatives? To this the father replied that he certainly knew about his cousin but he had died before the son was born, so how could it be relevant? The eyebrows of the father were thin and we asked if he wanted us to examine him. On his shoulder blades, there were two large leprosysuggesting anaesthetic lesions which supposedly neither he nor anyone else had noticed. 
The circumstance of leprosy being more common in certain lineages than in others was a recognized phenomenon, mainly understood in terms of there being a curse within the lineage, a curse transferable over generations.

One of the two recorded as 'released from treatment' in Gukulpur's new register was a woman in her mid-thirties from Pipalbot who had recently married into the village of Dhobata. Her paternal grandfather was affected by leprosy. He was ousted by the community, left for India, and was never heard of again. Some fifteen years later, her father developed leprosy signs and symptoms and there were plans of putting him out. He was saved by joining the party who in the mid-1970s set out for Anandaban hospital in Kathmandu. Later he had treatment (DDS) from the Gukulpur Health Post but defaulted. Several years later, she, his teenaged daughter, noticed a hypo-pigmented skin lesion on her body and soon there were several. They kept it quiet. "Very quiet," she said. But then some of her fingers started to contract and soon the villagers would not come near her. In 1990, she was started on MDT treatment from the Gukulpur Health Post and shortly after so was her father (a re-start). Both were subsequently 'released from treatment' (RFT). For years they were doing well but then the daughter got too close to the fire and there were blisters and then ulcers. Before her marriage into Dhobata (to a mentally challenged distant relative) she had another round of leprosy treatment and it was in connection with the second round that she was in the new register. The main ulcer did not heal and she lost the better part of a toe. In 2009, she said that she was not sure about the cause of her condition, but her father and others said that it was 'deotalagyo' (deity-caused), " and since I did not get well by the medicines, they were probably right." A year later, in 2010, she said that she had been fine after the last round of medicines. "The germs (kitaunu)", she said, "were dead." "Yet", she said, "I am afraid that it might come back", and added, "and I am ashamed because out of five siblings I was the only one who got the disease! Yes, there was leprosy in the lineage but why did I get it and why only me?" She, like most adults in the village, was unfamiliar with the idea of 'genes' and variations in gene sets.

In late 2009, a cholera epidemic swept through the district. During the first critical days of the epidemic the Sub-Health Post was closed as its personnel were away fighting the outbreak in other parts of the district. In Dhobata alone, four villagers died and another 30 were seriously ill. One of those who died was the Dhobata pandit. He was the one who, in 1996, had suggested that he had subjugated some less serious kinds of leprosy. During our years of absence, he himself developed the disease. 
In early 2009, he suggested that his condition was 'deotalagyo' (deity-caused) and most likely because of "the curse of the Chhetri's wife." He had been in the process of selling some land to the family of a Chhetri man and in the last minute he had changed his mind. The curse, he said, originated with the wife, now widow, of the prospective buyer, "a woman whose husband had leprosy." Only three years after the first noted symptom did the pandit seek allopathic help. Before that, he had funded an elaborate 'jhankri pooja' (a shamanistic ritual) but to no avail. Some fingers had contracted and there were badly infected foot ulcers. He by-passed the Health Post and went directly to the District hospital. Being an important man, he was straight away admitted for ulcer care and septic surgery. His name was not entered into the leprosy register.

In 2010, after the death of his father, contrary to what the pandit had told us a year earlier, his son claimed that his father's condition was 'a disease' (rog) and nothing else and that his father had said the same. He further suggested that there was no other case of leprosy in the kinship group. However, we knew that his father's first cousin and the cousin's son had been in the party who set out for Kathmandu in the mid-1970s. The pandit's son never gave us a straight answer as to his knowledge about the leprosy of these relatives.

The earlier mentioned Dhobata Kami had died but not from cholera. He never went to the District hospital for a diagnosis. Instead, he staged ' $a$ big pooja'. His relatives explained that having said that it was 'deotalagyo' there had to be a pooja or the person might die. Moreover, to ensure that the condition would not transfer to another person, the pooja had to include a sacrifice of a sizeable animal. The high caste villagers spitefully said that the Kami died a year after the big pooja because a lack of food (all resources spent on the ritual). His wife said that he died after a week of high fever.

The Dalit woman living outside her village had also died. She was buried without rituals. In 2010, we heard that her daughter had developed leprosy. She had a bare patch on her skull. She had not dared to have it examined. Having learnt that we were in Dhobata she came accompanied by her sister-in-law. We examined her and were happy to inform her and others that there were no signs of leprosy.

The District Master leprosy registers (not in the best of conditions) in the district headquarters, contained 22 registrations for the Dhobata administrative unit from 1996-2009. In 2010, most likely, locally there were as many persons affected by leprosy as during most of the preceding 15 years. However, several of those 
with severe impairments had passed away and there were less visible disabilities among new cases and thus in the villages, 'leprosy' was less evident. There was an overall expectation of leprosy being on its way out, an expectation nurtured by radio messages about Nepal having reached 'the leprosy elimination goal.' A message believed by many to mean 'no more leprosy' (see F.Houghton and M. Winterburn, 2020, for a recent article on the subject).

Since there were fewer disabilities among new cases, most of them were able to contribute to the household's economy. Even so, leprosy was still a stigmatized and stigmatizing disease and those able to conceal the condition did so, some by being examined and treated outside the district.

This was the case of a woman in the off-shoot hamlet of Dhobata interviewed in 2009. The first signs, she said, were jhum-jhum and then blisters on both legs. For a couple of years nothing was done about it and then she and her husband by-passed the District hospital for a hospital in one of the neighboring districts, and from there she had her leprosy treatment. She reported that during the 12-month treatment period she mostly stayed inside the house, had her own eating utensils, and slept by herself. In 2009, there was partial sensory loss in her feet and a weakness of one hand, but no deformity. She seemed convinced that no one outside the family knew about her condition. Some, however, did and some also knew that in her village of origin, an elder brother of hers had had leprosy and, most likely, so had their father.

In 2010, using the original questionnaire, with two added questions, and the same sampling criteria, we repeated INF's 1979/89 Leprosy Knowledge and Attitude Survey in the Dhobata ward previously surveyed. Fifty residents were interviewed. Thirty-five were high caste, 14 were Dalits, and one was from an ethnic group. The 1989/90 data from various parts of the district indicated that more than $90 \%$ feared leprosy more than any other disease. The corresponding percentage in the one-ward survey in 2010, with no significant difference in relation to age or caste position, was $54 \%$. One third, mainly men (13 M, 1 F) ticked HIV/ Aids as the disease they feared the most.

There were seven alternative replies to the question "Leprosy is caused by..." Sixty-eight percent ticked 'bacteria' (kitaunu) but never as the only alternative. A great majority, like in 1979/80, ticked more than one suggestion (a mean of 3.4). According to our understanding, not in the expectation that all suggested causes would necessarily be involved in every case but rather in the sense that there was a pool of possible causes, some at work in some cases and others at work in other cases. However, it highlights 
the understanding that there is rarely a single cause version but rather a multi-causal folk model in contrast to the mono-casual medical one.

There were four alternative replies to the question "Can leprosy be cured?" In the earlier survey only two percent marked "Always." Thirty years down the line, in the one-ward survey, the corresponding figure was $32 \%$. Twenty-seven percent marked "Sometimes"; 25\% "Don't know", and 16\% "Never".

One added question was: "If a person has completed leprosy treatment and gets an ulcer - does he/she need more leprosy medicines?" Seventy-two percent ticked 'Yes'.

\section{In 2016 and 2018}

In 2016, a new building for the Gukulpur Health Post was in the making. The Dhobata Sub-Health Post, like all Sub-Health Posts in the country, had become 'a Health Post', but without much change in services rendered. Meanwhile, in the district headquarters private medicine shops and clinics had multiplied.

The District Master leprosy register had only two entries for the Dhobata administrative unit between 2010 and 2016. The recording, however, was not complete. One of the two recorded names was that of a man whom we had interviewed in 1996. Some years before the 1996 interview, he, according to the old register, had completed a pauci-bacillary treatment (six months MDT). He himself, however, said that he had defaulted. He wanted the 2016 interview to be in a secluded place. A few years earlier, quite suddenly, he said, there had been jhum-jhum in his right leg and a year later some anaesthesia. In his heart, he said, he knew that his leprosy was back. Even so he waited a year and then made his way straight to the INF hospital in Surkhet where he was diagnosed as a multi-bacillary case. He had since completed the treatment (twelve months MDT). He said that forty years ago his maternal uncle had leprosy but had not been isolated as he was a respected person in the community. His own social standing, however, was not that strong. He worked as a peon in the local school and was afraid to lose his job. In addition, even now, he said, he was not sure that he was completely cured as some lesions were still there. "The leprosy," he said, "might be because of some unknown sin in the past."

In 2016 and 2018, some of those earlier interviewed were re-interviewed but now with a focus on signs and symptoms and health-seeking efforts

\section{AMC Journal, Volume 2, Number 1 (2021)}


prior to the leprosy diagnosis. Moreover, six recent patients $(4 \mathrm{M}, 2 \mathrm{~F})$ were contacted and interviewed on the same topics.

One of those re-interviewed was the young man who in 2009 had visited us together with his father. In 2009, we had understood that his facial nodules had developed suddenly. However, in now probing the subject we learnt that first there was jhum-jhum, then blisters, then skin patches, and then facial nodules. In between he had tried home treatment with ghee, herbal pastes and ointments, had been to a medicine-shop, had visited the District hospital, and had been to yet another medicine shop. Only in connection with the appearance of the facial nodules had he consulted the hospital in the neighboring district (earlier referred to) and only then was his leprosy diagnosed. In and through it all, he had not been to a shaman. The reason, he said, was that he had not done anything 'bad' so how could his condition be from the gods.

Meanwhile, his father had not followed our advice to speedily make his way to the District hospital for a diagnosis. He only did so five years later, despite an increasing number of symptoms similar to those of his leprosy-diagnosed son. He died, shortly after his visit to the District hospital and never got started on MDT. According to the son, the father had postponed the visit to the District hospital because the symptoms were not all that bothersome and he did not want others to learn about his condition. Leprosy meant 'a shameful condition' which when known to others would inevitably result in a loss of social prestige, not only for the person but also by association for the family. There would be talk behind their backs and expectations of various forms of discrimination. In Dhobata and its surrounding villages, as in most of Nepal, 'silence' is an age old strategy to prevent others from knowing what one does not want them to know (Miller, 1987).

In 2016 and 2018, leprosy was not very visible in the area. Almost all those with severe deformities, the pre-treatment generation, had passed away. However, the traditional image of a leprosy affected persons as a person 'without hands and feet' was still around but alongside a growing awareness of some leprosy patients having less obvious signs and symptoms.

At the same time, those able to conceal a leprosy diagnosis did so, some with greater success than others, and some seemingly believing that they were more successful than they were. At the same time, not to embarrass the person/family, others might not let on that they were in the know (mutual concealment).

The latter was the case in connection with a woman in her late thirties in one of the neighboring villages. A distant relative of hers secretly told us 
that she was likely to have leprosy, 'untreated leprosy' it was said. The first part was true the second was not as she, two years earlier, had completed a full course of MDT (12 months). She said that no one, except her husband, not even her teenage daughter (in the same house) knew about her leprosy. She concealed, she said, because "people may hate" (hela garnu). The leprosy diagnosis, she suggested, had been a complete surprise. At the time, she had thought that the symptoms were caused by gas in her stomach because of cold weather. She knew that her father's elder brother (in her village of origin) had had leprosy (excommunicated) but that was some fifty years ago and the idea of her own condition possibly being leprosy, she said, had not entered her head. "So today, what do you think caused your disease?" Her somewhat surprising answer was, "Pollution in connection with giving birth."

The Gukulpur Health Post's leprosy register could not be found. There had been a change of staff and things had been packed away for the move into the new building. The search, however, unearthed the patient card of a young woman, 'released from treatment' in 2015.

The first symptom, she told, was a skin lesion with sensory loss. It was not painful and only a year and a half later, as it started to increase, did she inform her husband. He brought her to Gukulpur Health Post where he occasionally worked as a peon. Its new staff, however, had no leprosy experience. Some ointment was provided and they were told to make their way to the District hospital if there was no improvement. However, at the District hospital there was also a lack of leprosy skilled staff and they were advised to turn to the INF hospital in Surkhet, which they subsequently did. The leprosy diagnosis, she said, was a complete surprise. "There were only skin lesions", she said, "... and no previous leprosy among my relatives." About the cause of her leprosy she suggested, "Weakness of the body combined with bad blood."

For others, the route to the proper diagnosis was even longer and that in spite of strongly leprosy-suggestive signs and symptoms. This, for instance, was the case of a young man in one of the nearby villages whom a Female Community Health Volunteer asked us to have a look at. He was working in India at the time of the first symptom, a swollen hand. Then there were blisters, then jhum-jhum and lesions with sensory loss, then muscle wasting and contraction of two fingers, then a blister which turned into an ulcer, and then jhum-jhum in both feet. Meanwhile in India, where he worked on and off, he had been to four medical clinics without a correct diagnosis. In Nepal he had consulted five shamans, one after another, been to the Gukulpur Health Post, and to a herbalist (vaidhya). People around him were aware 
of his signs and symptoms. None, he said, had suggested leprosy. Since all his health-seeking efforts had failed, he, like most people around him, he said, thought that most likely "the god of his stepmother" was behind his troubles. His father had married two women. The first had not given birth to a child and he was the child of the second wife. To save himself, he and his family had left his father's house and moved in with his mother-in-law. We directed him to the nearest INF hospital where he was immediately classified as a highly multi-bacillary case (infectious), and he was admitted for ulcer care.

A red, swollen, and shiny face sometimes resulted in leprosy rumours, particularly if there was known leprosy in the family. In 2016, we learnt about three such cases, all men, two of them brothers, within the Dhobata administrative unit.

The father of the two brothers had visible deformities. The eldest of the two brothers had had four years of leprosy treatment as a child. After that, he was doing well and the villagers (Pipalbot) did not avoid him. Now, decades later, rumors suggested that his leprosy was back and perhaps his younger brother had also developed the disease. In the hope of getting away from whatever was haunting him, the elder brother and his family left his parental home and moved to the other side of the village. Before that there had been several visits to the nearest medicine shop intermingled with shaman consultations. Upon our arrival we were told that he had gone to INF's hospital in Surkhet for leprosy treatment. This, however, was not correct. Besides a red face and supposedly new skin lesions, he had epilepsy and had recently fallen into a fire and he was away for treatment of the burns. The younger brother was also out of the village. He, the villagers said, had been to more than one shaman and several goats had been sacrificed. In between he had also been to the nearest medicine shop.

The deceased father of the third person, had also had leprosy and before him so had his father's maternal uncle (one of the last ones 'drummed out' of Dhobata). The mother of the third person was 'the wife of the Chhetri' who the Dhobata pandit accused of having brought about his leprosy by a curse. Now, at approximately the same age as his father had been when started on leprosy treatment, the son had symptoms which might indicate leprosy. He had been to the Gukulpur Health Post where he had been told to report to the District hospital. However, a year later, he had not done so but had tried various herbal treatments and also anti-allergy medicines from more than one medicine shop. 
Our Dhobata host was skeptical, "Most likely it is leprosy," he said, "and ifleprosy, he is likely to stay away for some time, at least during the treatment period."

In 2018, we were told that the rumors were wrong. The allergy medicines had healed the face of the younger Pipalbot brother and the elder one was also fine except for an ugly burn ulcer (having fallen into the fire). The Dhobata man was away in India but relatives reported that whatever had been wrong had sorted itself out and he was doing well.

A year later, the elder brother and his father were both admitted for inpatient care at INF's Surkhet hospital, not for another round of leprosy medicines, but for ulcer care. Rumors and discussions in Dhobata and its neighboring villages, however, were not likely to distinguish between the two.

\section{Conclusions and Suggestions}

Leprosy has been a part of Nepal's history and society since time immemorial (see web site Leprosy Control Division, Department of Health Services). However, during the last few generations, the leprosy situation has drastically changed, and so also in the remote district of Jajarkot. In the area studied, the turning point was the introduction of leprosy medicines, an introduction which took place 40 years ago. It was preceded by centuries of hope for magic-religious rituals to soften the Karmic curse and to placate lesser divinities which might have brought on the condition. At the same time, leprosy was recognized as the 'Maha rog', the Big Disease, not likely to be reversed. And, in the great majority of cases, there was no healing but a progression of the disease. Society's response, when possible, was to protect itself by removing 'the cursed, the inauspicious, and the ritually polluted and polluting ones'. However, by the time a removal was executed, others might well have been infected and there would be new cases. Likewise, there will continue to be new leprosy cases if the delays of present undiagnosed patients are not shortened. Yet, the scenario is not the same as 40 years ago.

Intellectually and physically the researched area is closer linked to the outside and will continue to be so. And, in regard to leprosy, great changes have taken place. Locally, leprosy is far less evident and that in spite of no more excommunications. The pre-treatment generation, commonly marked and recognized by severe disabilities and frightening deformities, have passed away and the newer generation of those affected by the disease have less impairments and disfigurements and their number is far lower than the previous accumulation of advanced leprosy cases.

\section{AMC Journal, Volume 2, Number 1 (2021)}


The arrival and utilization of leprosy medicines changed the situation. And, most of those affected have been on leprosy medicines for longer or shorter periods of time with less permanent physical damages as a result. However, the leprosy skills of those who should be able to recognize and diagnose the disease in its early stages, the private and public health service workers, have often not been up to standards and evidently this is still the case. Thus, often there is a delay in the start of leprosy treatment and concurrently a window for transmissions. And, there are other holdups. One is connected with early signs and symptoms of the disease often being non-intrusive. Another is the circumstance that the early signs and symptoms are not recognized as possibly being leprosy or indicators of the disease. In addition, the circumstance of leprosy being expected to run in certain lineages and not in others is also a delaying factor, in the latter case because leprosy is not an anticipated possibility and in the former because the lived in history of leprosy within the lineage, social stigma included, is likely to deter early presentations. Additionally, but very importantly, allopathic medicine is a latecomer on the local scene and not well understood. In relation to leprosy, as exemplified and illustrated in the main text, there are a number of crosscultural difficulties and misunderstandings which in part encourages parallel and delaying health-seeking within the magic-religious sphere. In addition, there are those who according to their understanding of the situation choose traditional healing methods rather than Western medicines. And thus, there is an accumulation of holdups and delays resulting in late leprosy diagnoses. Even so, over the years, the number of new cases has declined, however, not to the degree that there are no more transmissions but to a low but seemingly quite stable level next to the elimination goal of less than one case per 10,000 population.

If leprosy eradication is to take place within this or the next generation additional efforts are clearly needed. As the causes of long delays are multiple a multi-dimensional approach is needed. An upgrading of leprosy skills among private and public health service workers and also traditional healers is essential, but so is public leprosy awareness raising of early signs and symptoms of leprosy. Moreover, misunderstandings concerning the medical approach and its likely outcome need to be addressed. Concurrently, there is a definite need to realize and to acknowledge that for those affected, their families, and their communities, leprosy is far more than what is enclosed in the medical definition of leprosy. Dr Cardinalli's previously cited conclusion from the early 1980s of leprosy in the researched area being "... as much a social, cultural and psychological problem as it is a 
medical one" is still valid, even if the problems are less than previously. Even so, they need to be taken into account in all efforts to shorten delays and in all strategies to attain the ultimate goal of leprosy eradication. To reach the latter, a double approach of voluntary presentations parallel to and/or combined with some form of active case detection, like contact screenings, might well be needed.

\section{Acknowledgements}

The authors want to express sincere thanks to all patients and health workers involved in the project, to Buddhi Thapa, Laxman Thapa, and Udaya Nath Yogi, in particular. A special debt of gratitude is owed to Alan Barker for great editing. We also want to thank the Leprosy Research Initiative for their generous financial support (Ref.no:703.15.01) and the Nepal Health Research Council for ethical approval (Ref.no:1940).

\section{References}

Cardinalli, R. (1982). At the feet of the Lord Vishnu. Unpublished Report.

Cross, H., \& Choudhary, R. (2005). STEP: an intervention to address the issue of stigma related to leprosy in Southern Nepal. Leprosy Review, 76(4), 316-324.

Engelbrektsson, U-B. (2012). Challenged Lives. A medical anthropological study of leprosy in Nepal. Gothenburg: Studies in Social Anthropology 23, University of Gothenburg.

Engelbrektsson, U. B., Subedi, M., \& Nicholls, P. (2019). The challenge of health-seeking: recollections of leprosy inpatients in post-elimination Nepal. Leprosy Review, 90, 433443.

Houghton, F. \& Winterburn, M. (2020). Leprosy in Nepal: A re-emerging threat. Journal of Public Health Policy, 1-6.

International Nepal Fellowship (1981). Annual Report of the Leprosy Control Programme (Sharwan 2037 BS to Ashad 2038BS). Pokhara: International Nepal Fellowship.

Leprosy Control Division (2010). Annual Report 2066/67 (2009/10). Kathmandu: Ministry of Health and Population.

Leprosy Control Division (2017). Annual Report 2073/74 (216/17). Kathmandu: Ministry of Health and Population.

Miller, C. (1987). Decision Making in Village Nepal. Kathmandu: Sahayogi Press, Pvt. Ltd.

Ogden, J.A. \& Porter, J.D.H. (1999). Leprosy: Applying qualitative techniques to research and intervention. Leprosy Review, 70: 129-135.

Subedi, M. \& Engelbrektsson, U. B. (2018). Factors contributing to delay in diagnosis and start of treatment of leprosy: Analysis of help-seeking narratives from a community study in Dang district. Dhaulagiri Journal of Sociology and Anthropology, 12, 11-17.

Subedi, M. S. (2001). Medical Anthropology of Nepal. Kathmandu: Udaya Books.

Subedi, M. (2018). State, Society and Health in Nepal. London: Taylor \& Francis. 